
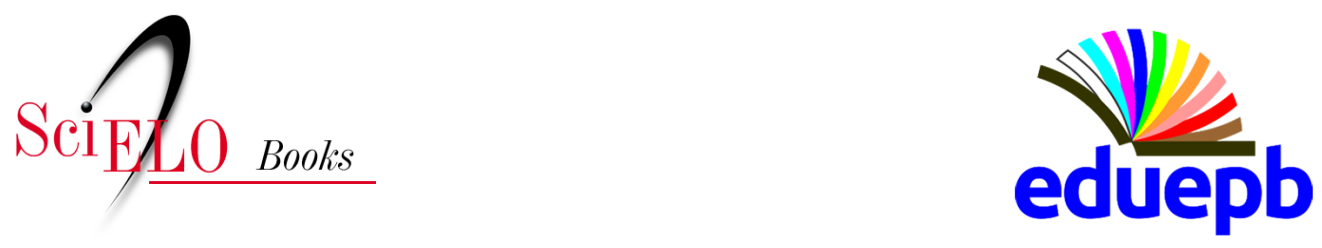

\title{
Introdução \\ Apontamentos para uma história da Esperança
}

\author{
Cidoval Morais de Sousa \\ Ivo Marcos Theis \\ José Luciano Albino Barbosa
}

\section{SciELO Books / SciELO Livros / SciELO Libros}

SOUSA, C. M., THEIS, I. M., and BARBOSA, J. L. A. Introdução Apontamentos para uma história da Esperança. In: SOUSA, C. M., THEIS, I. M., and BARBOSA, J. L. A., eds. Celso Furtado: a esperança militante (Depoimentos): vol. 2 [online]. Campina Grande: EDUEPB, 2020, pp. 19-35. Projeto editorial 100 anos de Celso Furtado collection. ISBN: 978-65-8622111-4. https://doi.org/10.7476/9786586221671.0002.

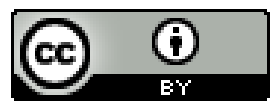

All the contents of this work, except where otherwise noted, is licensed under a Creative Commons Attribution 4.0 International license.

Todo o conteúdo deste trabalho, exceto quando houver ressalva, é publicado sob a licença Creative Commons Atribição 4.0.

Todo el contenido de esta obra, excepto donde se indique lo contrario, está bajo licencia de la licencia Creative Commons Reconocimento 4.0. 


\title{
Introdução
}

\section{Apontamentos para uma história da Esperança}

\author{
Cidoval Morais de Sousa \\ Ivo Marcos Theis ${ }^{2}$ \\ José Luciano Albino Barbosa $a^{3}$
}

\begin{abstract}
A S Diferentes leituras Já produzidas sobre Celso Furtado e sua obra apresentam, pelo menos, duas características comuns: concentram-se, de um lado, muito fortemente, nas obras de natureza econômica e, de outro, na atuação política do economista paraibano de Pombal, nascido em julho de 1920. Mesmo em textos com densidade biográfica o que prevalece é o Furtado culto, que desde cedo gostava de literatura, história e filosofia e que queria ser escritor. Ele mesmo economizou palavras sobre a sua vida pessoal em seus diários e, mais tarde, em sua obra autobiográfica. No volume 1 desta trilogia (Interpretações), que não tem nenhuma pretensão biográfica, a leitura corrente se manteve, com uma ou outra exceção. Dois ou três autores destacaram, em seus textos, características mais subjetivas do homem Furtado, como a paixão pelo que fazia. Neste volume 2 a regra geral também se mantém, mas com algumas exceções. A natureza da obra (Depoimentos) talvez explique os destaques fora da curva. Há um Furtado que, além de ser um gigante intelectual, um homem público honesto, coerente com seus
\end{abstract}

1 Jornalista, doutor em Geociências pela Unicamp, professor e pesquisador da Universidade Estadual da Paraíba (UEPB), vinculado aos Programas de PósGraduação em Desenvolvimento Regional e Ensino de Ciências e Educação Matemática. Colabora com o PPGCTS da UFSCar.

2 Economista, PhD em Geografia Humana pela Eberhard-Karls Universität Tübingen (Alemanha), docente-pesquisador do Programa de Pós-Graduação em Desenvolvimento Regional da Universidade Regional de Blumenau (FURB), líder do Núcleo de Pesquisas em Desenvolvimento Regional, editor da Revista Brasileira de Desenvolvimento Regional e Bolsista de Produtividade em Pesquisa do CNPq.

3 Sociólogo, Doutor em Sociologia pela UFPB, professor efetivo da Universidade Estadual da Paraíba (UEPB), vinculado ao Departamento de Ciências Sociais e docente permanente do Programa de Pós-graduação em Desenvolvimento Regional. 
princípios, zeloso pela coisa pública, um combatente implacável contra as desigualdades regionais, é, sobretudo, humano.

A primeira síntese que formulamos - depois da transcrição e edição das entrevistas aqui publicadas - foi que aquele homem, aparentemente, sisudo, elegante, sempre vestindo ternos de linho bem cortados, boa estatura, porte atlético, intelectual renomado no Brasil e no exterior, embora difícil de imaginar para quem o conheceu pelos livros (e não foram poucos), também experimentou a vida comum dos mortais. Assim, é estranho, por exemplo, imaginar Celso Furtado, doutor pela Sorbonne, em sua elegância, abrindo cancelas como passageiro de uma Rural Willys, em estradas precárias e ladeadas pela miséria, na imensidão seca do sertão Semiárido. Também não parece razoável um Furtado que 'faz conta' de centavos em empréstimo a um amigo, ou que se 'recusa' a pagar, em partes iguais, a conta de um almoço, sob a alegação de ter se servido a menos num pedido, digamos, para dois. E o que dizer de alguém que afirma, peremptoriamente, que o homem sério que dirigia a Sudene gostava de ouvir causos, ou que, em viagens a serviço, fazia questão de dividir o quarto de hotel, inclusive com subordinados, para economizar nas diárias.

E quem apostaria que aquele homem culto, amante das artes, que escrevia ouvindo música clássica, seria capaz de provocar constrangimento entre casais amigos justamente no meio de uma peça de teatro? E imaginar alguém escrevendo textos densos de teoria econômica, criticando, inclusive, "o modelo de Marx", em meio a folia do carnaval de Recife, no andar térreo de um prédio (o aluguel era mais barato), no bairro do Pina, enfrentando o barulho de blocos, la ursas e congêneres? E mais do que isso: convocar os amigos no final da terça-feira de carnaval para discutir o texto escrito durante a folia, considerar normal aquela situação e estranhar a reação dos convocados, ainda dispostos a aproveitar os últimos momentos do reinado de momo? E quem imaginaria Celso Furtado produtor e 'roteirista' de cinema? Pois é, os bastidores do filme Brazil: The Troubled Land, de Helen Rogers, acrescenta mais esta particularidade à vida do nosso homenageado, incluindo uma cena digna de um filme de faroeste, mas bem típica do sertão dos coronéis. ${ }^{4}$ Ou um Furtado que manda um dos filhos (Mário), recém chegado

4 Sobre o filme, na realidade, um documentário destacando a questão da terra no Nordeste, evidenciando a atuação das Ligas Camponesas, Celso Furtado o veria na sala de exibições da Casa Branca, na companhia do presidente John F. Kennedy. O Brasil não veria o filme ao longo da ditadura militar e Furtado seria acusado, por 
do Rio de Janeiro, passar o Natal com a família de um dos seus colaboradores na cidade mais seca do Semiárido (Cabaceiras), sob a alegação de que, mais do que um final de ano com o pai no Recife, ele precisava conhecer a realidade do Cariri?

Este segundo volume, como sinalizamos acima, se não coloca a figura humana que foi Celso Furtado em primeiro plano, não descura dela no sentido das tessituras de suas relações sociais e também afetivas. Para toda uma geração que viu o golpe de 1964, Furtado era prestigiado em razão de suas posturas republicanas e democráticas. A relação entre a vida corriqueira e as letras permitiu o surgimento de uma visão de mundo que o fez refletir sobre o Nordeste de maneira diferente daquilo que até então era pensado. A vida que teve, ainda quando menino em Pombal, e a que experimentou no cenário paraibano, marcada pelas oligarquias rurais, as relações paternalistas e a violência no campo, ofereceram, à criança e ao jovem, os elementos para a elaboração de um espelho em si, cujo reflexo foi lançado na forma de análises e posturas éticas. É possível entender que, como ocorreu com outros escritores, a exemplo de Ariano Suassuna e Graciliano Ramos, a presença forte da memória da infância foi a primeira fonte de inspiração e de trabalho, uma companhia permanente em suas vidas literárias. Tal como Itabira para Carlos Drumond de Andrade; Pilar para José Lins do Rego; Quebrangulo, Buíque e Palmeira dos Índios para Graciliano Ramos; Taperoá e Recife para Ariano Suassuna; assim também foi Pombal e o Sertão Semiárido para Celso Furtado.

Seja como memória, seja como sotaque e escrita, o que "escutamos" neste volume nos permite uma segunda síntese: Furtado fez uma espécie de reconciliação com o passado. Um acerto de contas que se atualizou no processo. O poeta Vinícius de Moraes certa vez afirmou que o samba expressa dor, saudade, perda. Seu gênero não se constrói na piada. $\mathrm{O}$ samba possui forma de oração. Tal musicalidade e poesia, decorrentes do sofrimento no cativeiro, da escravidão do negro, serviram de base e combustível para o seu nascimento. Essa ilustração se faz oportuna porque os autores mencionados acima conceberam sua origem de forma trágica. O Nordeste para Ariano Suassuna, Graciliano Ramos e Celso

alguns setores da esquerda de, ao colaborar com a cineasta Helen Rogers, ter colaborado, indiretamente, com a CIA, em sua missão de evitar que o Brasil virasse uma "nova Cuba". Outros detalhes sobre o documentário ver entrevista de Juarez Farias (primeira deste volume, p. 39-70), e sobre a ajuda americana à Sudene e o comunista Furtado, conferir entrevista de José Mário Aragão (quinta entrevista, p. 141-166 ). 
Furtado é uma tragédia, especialmente no sentido de como os gregos a entendiam. Quer dizer, aquilo que problematiza valores e conceitos, que exige de cada um a capacidade de se redefinir diante do impacto causado pela quebra de ilusões perenes. Em outras palavras, a tragédia possibilita a catarse. Nas obras dos autores citados há, por assim dizer, uma catarse sociológica, moral e simbólica do Nordeste, um estranhamento diante do que se anunciou como realidade, problematizando-a ao extremo, com interpretações que superam o trágico pelo encantamento de observá-lo. O homem de aspectos agrestes na aparência se revelava como cacimba a minar água doce em momentos de sequidão. Assim era Furtado: generoso, discreto, seco, objetivo, convicto, incansável, na vida real da memória de seus interlocutores.

A leitura das vozes e memórias deste volume ainda nos permite uma terceira e última síntese: em todas as épocas e em todos os lugares devem ter existido mulheres e homens que se recusaram a aceitar o mundo no qual se encontravam. Citam-se, com frequência, Thomas Morus e os socialistas utópicos que precederam a Marx. Poderíamos (e deveríamos) citar as beguinas, entre elas, Marguerite Porete. Aliás, deveríamos citar mulheres e homens rebeldes e inconformados de outras culturas, que viveram nas Américas, nas Áfricas, nas Ásias. Se não tivessem existido essas mulheres e homens, o mundo, possivelmente, seria pior do que é. $\mathrm{O}$ que, em todas as épocas e em todos os lugares, tem movido muitas mulheres e muitos homens é a esperança. Malgrado o fato de a palavra ter se desgastado "um bom bocado", como diria o poeta, de ter se banalizado o seu emprego, de ter se modificado seu conteúdo e seu significado, ela ainda pode expressar essa disposição 'demasiadamente humana' de insurgência contra o estabelecido. "A esperança é a última que morre", diz o ditado popular. Talvez, em comparação com outros afetos que rapidamente se encerram, seja ela o que venha experimentando surpreendente perenidade para acudir mulheres e homens quando o mundo à sua volta vai se tornando insuportável.

Pindorama é um lugar e(m) um tempo que foi inventado por três raças tristes. E que vêm buscando viabilizar-se, desde o advento da modernidade eurocentrada, no concerto das formações sociais submetidas ao governo do deus-capital, como uma parte digna da periferia. Com a promessa-esperança de converter-se numa terra sem males. Celso Furtado é um desses seres humanos que, num dado instante, na linguagem dos poetas populares, "caiu do céu nublado" para acrescentar substância à esperança que, um belo dia, levará as três raças tristes à 
redenção. Sua trajetória não seria ignorada. Evidentemente, não por seus detratores e algozes - sim, em todas as épocas e em todos os lugares, sempre existiu quem defendesse seu pequeno paraíso amparado na tristeza. Mas, surpreendentemente, também não por quem intuiu (e intui) que "a esperança é a última que morre". Armado com seus princípios e valores, Celso Furtado nunca frustrou a quem tinha apenas a esperança em que se agarrar!

\section{Aspectos do método}

A realização deste volume - o segundo da trilogia Celso Furtado: a esperança militante - só se tornou possível graças a um conjunto de parcerias institucionais e a colaboração, direta, de colegas professores e estudantes da pós-graduação em Desenvolvimento Regional da UEPB, da FURB e da UFRJ. O grande desafio foi construir uma lista de possíveis entrevistados e cotejá-la com aquilo que, na nossa concepção, deveria ser o eixo de sustentação do livro: considerando que a proposta, desde o primeiro volume, era revisitar fatos e interpretações, jogar luz sobre questões aparentemente controversas e, sobretudo, oferecer contribuições para uma história recente do Brasil e suas instituições, a partir da vida e da obra de Celso Furtado, as pessoas a serem entrevistadas precisavam, minimamente, ter se relacionado com o nosso homenageado (colaborado, assumido missões e funções técnicas, assessorado, estudado) em, pelo menos, um dos momentos de sua carreira técnico -político-acadêmica (Cepal, BNB, Sudene, Ministério do Planejamento, exílio, Ministério da Cultura).

A lista se revelou extensa, principalmente depois das primeiras entrevistas. Cada entrevistado também colaborou indicando novos nomes e viabilizando contatos. Infelizmente, muitos já não estavam mais entre nós e outros, em idade avançada e com problemas de saúde, não puderam participar do projeto. Contamos, nesse processo, com a colaboração essencial do Professor Marcos Costa Lima, da UFPE, que coordenou, recentemente, um grande projeto de pesquisa sobre o Conselho Deliberativo da Sudene - Condel, denominado de Procondel. ${ }^{5}$

5 O Procondel (http://procondel.sudene.gov.br/) foi o projeto de preservação e disponibilização do acervo do Conselho Deliberativo da Sudene - Condel, período 1959 - 2000, realizado pela Sudene em parceria com a Universidade Federal de Pernambuco, entre 2013 e 2016, e tinha como meta a preservação desse acervo e a 
A mediação entre a nossa proposta e os achados projeto foi feita pela professora Ângela Nascimento, coordenadora executiva. O acervo de entrevistas inéditas é muito rico. $\mathrm{E}$ foi nele que recolhemos alguns dos melhores depoimentos deste volume, como os de Francisco de Oliveira e Aldo Ferrer, já falecidos. Com os devidos créditos, e externando a nossa gratidão pela parceria, aqui tentamos contribuir para universalizar uma parte desse acervo, visando subsidiar análises, discussões, construção de novos conhecimentos, leituras de políticas públicas e fixação de diretrizes de desenvolvimento regional na academia, governos e, também, nos diferentes grupos da sociedade civil.

\section{Organização da obra}

Há quatro conjuntos de depoimentos neste volume. O primeiro se caracteriza pelas entrevistas que a equipe do Projeto Editorial 100 Anos de Celso Furtado realizou entre dezembro de 2019 e março de 2020, cuja ênfase reside na relação direta dos entrevistados/as com Furtado, com destaque para reminiscências, legados e influências teóricas e políticas. O segundo é composto pelas entrevistas realizadas pela Equipe do projeto Procondel, que se concentram, por sua vez, na experiência dos personagens no contexto de criação e funcionamento da Sudene, antes e depois da cassação de Celso Furtado pela ditadura civil-militar, em 1964. O terceiro é formado por pronunciamentos recolhidos ao longo dos últimos anos, no Brasil e no exterior, em eventos (seminários, aulas, homenagens) de importância inequívoca para a compreensão de contextos de obras e realizações, influências, características pessoais e profissionais do nosso homenageado e questões que permaneciam com divulgação restrita. E, por fim, um quarto tipo, que não resultou de entrevista direta, mas foi escrito por alguns seguidores de Furtado, no formato de depoimento, exclusivamente para este volume. Tanto as nossas entrevistas quanto as realizadas no contexto do Procondel foram gravadas em vídeo e áudio, transcritas e, em alguns casos, editadas com a supervisão dos entrevistados, preservando o conteúdo e, sempre que possível, as características da linguagem oral.

A distribuição, neste livro, do material recolhido não seguiu, necessariamente, a ordem da classificação acima, mas também foi articulada em quatro blocos. No primeiro, reunimos aqueles a quem chamamos

universalização do seu acesso, coordenado pelo professor doutor Marcos Costa Lima e pela professora mestra Angela Nascimento. 
de pioneiros - pessoas que foram convidadas (ou como elas preferem dizer, "convocadas" ou "chamadas") por Celso Furtado antes mesmo de a Sudene existir de fato, e aqueles que chegaram no contexto da criação e primeiro Plano Diretor. Demos a esse bloco o título de Aprendendo e fazendo com o mestre. Estão nele, pela sequência, Juarez Farias, Francisco de Oliveira, Otamar de Carvalho, José Maria Aragão e Carlos Miranda. No segundo, Influências e Legado, juntamos quem participou da experiência da Sudene com e pós-Furtado, acompanhou sua trajetória no Ministério do Planejamento e, pós-exílio, a sua participação no Ministério da Cultura. Pela ordem, Adalberto Arruda, Leonides Alves, Paulo de Tarso, Manelito Vilar, Tania Bacelar e Ângelo Oswaldo. No terceiro bloco reunimos quatro atores importantes para pensar Furtado fora do Brasil e discutir a influência de seu pensamento na América Latina e na Europa. Estão em Do Brasil para o mundo o economista chileno Osvaldo Sunkel, o argentino Aldo Ferrer (já falecido), outro economista chileno, Gonzalo Martner, e o sociólogo estadunidense Immanuel Wallerstein (também já falecido). Por fim, em Utopias Furtadianas, publicamos depoimentos dos economistas Luiz Gonzaga Belluzo, Jorge Santana, José Ramón García Menéndez e Carlos Lessa, que morreu pouco antes do fechamento deste volume.

Tentaremos, nos próximos parágrafos, fazer uma síntese dos conteúdos das entrevistas, apresentando, desde já, três advertências: primeira, embora tratem, às vezes, do mesmo tema, não implicam em leitura sequencial; segunda, não tivemos (e nem alimentamos) a pretensão de esgotar assuntos ou temas, o que significa dizer que a história (ou as versões contadas do mesmo fato) permanece aberta; e, a terceira, nossa pretensão não foi necessariamente esclarecer, mas, sobretudo, contribuir com uma agenda de pesquisa e uma história (do Nordeste, do Brasil, da América Latina) que ainda está por ser contada.

\section{O que dizem de Celso Furtado}

O advogado e economista Juarez Farias abre o primeiro bloco de entrevistas. A memória impressiona e a narrativa prende os interlocutores. Farias conta como foi convidado para a aventura da Sudene, o que fez no GTDN, como participou da construção dos dois primeiros planos diretores da Sudene, sua contribuição para o primeiro Plano Trienal (do Brasil) e como foi o enfrentamento da primeira seca pós-

criação da Sudene. Além disso, revela um Furtado mais humano que técnico, zeloso, não apenas com o dinheiro público, mas também com 
o seu próprio. Relata fatos curiosos (e polêmicos), como o dia em que a Casa Branca exibiu um filme - Brazil: the troubled land -, tecnicamente "co-produzido" por Furtado, e, também, como este escreveu um capítulo do livro Desenvolvimento e sub-desenvolvimento num carnaval do Recife. Com emoção, Farias encerra falando do significado do economista paraibano em sua vida: "foi uma graça que eu recebi. Trabalhar com ele foi uma honra. Mesmo quando discordávamos, eu achava que ele estava querendo me ajudar".

A chegada de Francisco de Oliveira à equipe liderada por Celso Furtado é contada aqui em mais de uma versão: a do próprio Oliveira, uma outra rica em detalhes narrada por Juarez Farias, e uma que aparece nos fragmentos de várias outras entrevistas. O certo é que, para Oliveira, toda a adjetivação possível sobre o homem e sua obra é que Celso Furtado era um republicano exemplar. Numa tradição brasileira de patrimonialismo, ele (Furtado) era uma "exceção luminosa". Nos cinco anos em que trabalharam juntos, Oliveira afirma que aprendeu "o que é república e o que é democracia, sem nenhuma retórica”. Segundo ele, a história que fica da Sudene, tal como seu fundador, é de uma instituição extremamente republicana. Ou era uma missão para um demônio ou para um santo. E Celso Furtado era as duas coisas. Demônio para aquelas tradições patrimonialistas, e santo para as novas oportunidades que a Sudene veio criar."

Na leitura de Otamar de Carvalho, a Sudene de Furtado teria caráter extraordinário, ou seja, duraria o tempo necessário à implementação das mudanças que motivaram a sua criação. Embora oficialmente criada em dezembro de 1959, a Sudene, segundo Carvalho, tem raízes nos estudos realizados, até aquele momento, pelo economista baiano Rômulo Almeida; nos estudos do Padre Joseph Lebret e do agrônomo Guimarães Duque e, também, nas pressões políticas de diferentes setores da sociedade nordestina, destacando-se, dentre eles, as Ligas Camponesas e o movimento dos Bispos do Nordeste, liderado por Dom Helder Câmara. A Sudene, com Furtado, pensava o desenvolvimento em novas bases, para além das obras de infraestrutura e da chamada solução hidráulica. Otamar de Carvalho traz um Furtado humilde, que respeita a fila de elevador e tem sensibilidade para boas histórias e causos. Para ele, a Sudene funcionou com prestígio até março de 1964. Mas o projeto se desfigurou depois do golpe civil-militar. A instituição perdeu força política, chegou a ser extinta (2001) e, desde que foi recriada (2007), ainda não disse a que veio. 
Para o economista José Maria Aragão, que fez seu discurso de formatura em economia no Rio de Janeiro, em 1959, recuperando um debate, famoso à época, entre Celso Furtado e o inglês Ragnar Nurkse, o convite para trabalhar com Furtado teve "o valor de um chamamento". Aragão pretendia, naquela época, seguir carreira diplomática, mas "a oportunidade de integrar a equipe fundadora da Sudene teve um atrativo muito especial". A Sudene, naquele momento, era o principal assunto da imprensa nacional: uma instituição para o planejamento que tinha o papel de conferir uma dimensão regional aos projetos antes apropriados, individualmente, pelos governos estaduais. Isso representava, na visão de Aragão, uma reforma administrativa de grande vulto porque, pela primeira vez, um grupo de governadores se reunia de forma orgânica em um colegiado para discutir os problemas da região.

Em sua entrevista, Carlos Miranda diz, também tentando controlar a emoção, que se orgulha de ter tirado a melhor nota de sua turma no curso de Técnico em Desenvolvimento Econômico (TDE) com o mestre Furtado, e de ter feito parte do primeiro grupo de técnicos da Sudene. Para ele, uma coisa importante em sua relação com o economista paraibano foi compreender a importância do território como identidade política das pessoas. "Elas se identificam com o lugar, são mais o lugar onde vivem do que qualquer outra coisa. Eu aprendi o que é pertencer quando entrei na Sudene", afirma. Celso Furtado, segundo Miranda, partiu desse sentimento de pertencer, que "leva a uma série de outros desdobramentos”. Miranda também testemunhou fatos relacionados à dimensão humana de Furtado e considera que um dos grandes feitos políticos da Sudene foi criar o Departamento de Agricultura e Abastecimento. Ali, diz ele, "a gente conseguia unir questões operacionais, práticas e pragmáticas sem se desligar das questões políticas e teóricas do desenvolvimento".

Formado em direito e economia, Adalberto Arruda, na entrevista que abre o segundo bloco (Influências e legado), lembra que Celso Furtado tinha uma proposta de mudança que encantava: "não era por meio da violência, como alguns setores da esquerda pregavam; era um processo, digamos assim, democrático". O Brasil, naquele momento, "era um arquipélago econômico-social, com regiões com níveis diferenciados de desenvolvimento, e isso era ruim para a integração nacional”. E essa integração "só podia ser feita com a ação forte governamental". Das lições, Arruda destaca: "Furtado sempre dizia: mais importante do que ter, é ser; mais importante do que ser, é construir, é fazer. Porque fazer é uma 
forma de ser. Ser e fazer estão conjugados. Ninguém tem valor essencial pleno se não for também um construtor". Sobre o futuro da Sudene, é lacônico: "eu tenho amigos que acham que o projeto Sudene já acabou e que a Sudene deveria ser colocada na prateleira para ser julgada pela história".

Na segunda entrevista do bloco, Leonides Alves da Silva Filho defende que a Sudene foi uma instituição que criou uma alternativa de tratamento diferenciado para os problemas de desenvolvimento do Nordeste. $\mathrm{O}$ único tratamento que existia na época tinha como enfoque político o aumento da oferta d'água e era gerenciado pelo DNOCS. A Sudene, segundo Silva Filho, contribuiu "para gerar uma mentalidade e uma abordagem global e evitar o pires na mão". Na sua leitura, a criação da Sudene não foi obra da vontade pessoal do presidente Juscelino Kubitschek. "Ele foi pressionado a criá-la em função das secas simultâneas, do contexto internacional, das tensões sociais na região, como o movimento das Ligas Camponesas, comandadas por Francisco Julião, e a influência da Igreja Católica", afirma. Do legado furtadiano destaca a capacidade de negociação e articulação, que "transformou o que era predominantemente planificação estatal em uma ação planificadora global, envolvendo a integração entre o setor público e o setor privado. E incutiu isso no corpo técnico da Sudene".

No capítulo seguinte, Paulo de Tarso, que chegou à Sudene em 1963, afirma que Celso Furtado não só estava convencido, como convenceu a todos de sua equipe, de que o problema do Nordeste "não era apenas de acumulação de água ou de carência de obras contra as secas; havia de se fazer um esforço de planejamento". Era melhor para o país o desenvolvimento da região como um todo "do que a eterna ajuda por ocasião das secas”. O relatório de Furtado (o GTDN), de acordo com Paulo de Tarso, mostrava que "se houvesse uma ação articulada, uma ação coordenada, em que otimizássemos a aplicação dos recursos, haveria de ser melhor". Na sua leitura, a Sudene foi a instituição que criou as condições para operacionalizar a integração regional. Da herança de Furtado, destaca a lógica do planejamento, a metodologia de trabalho e um corpo técnico profissional, altamente qualificado, "que deu consequência as políticas implementadas".

O agropecuarista Manelito Vilar foi um dos primeiros engenheiros da equipe montada por Celso Furtado, encarregado de cuidar, na Sudene, de questões relacionadas ao saneamento e ao abastecimento de água. Bom de conversa, começou o depoimento lembrando que a sua 
relação com Furtado, no campo das ideias, foi de amor à primeira vista. "Celso Furtado não era contra a seca. E eu não era e nem sou contra a seca". Manelito afirma que, nessa questão, sempre defendeu "uma estratégia de convivência com ela”. Segundo ele, "agora é preciso passar um tempo. Uma sucessão de gerações operando nesse patamar para consolidar o caminho definitivo do Nordeste". Lembra que "havia uma pressão enorme" para que se definisse, na Sudene, uma política de açudagem. Era a prevalência do modelo hidraulicista. "Aí Furtado chegou e disse: a Sudene só vai definir uma política de açudagem para o Nordeste quando estiver definida a política de águas".

A economista Tania Bacelar destacou, em sua entrevista, quatro grandes influências de Celso Furtado em sua vida profissional e também pessoal: o exemplo do intelectual com o pé no chão, no sentido de que a realidade não é para estar distante do estudioso, do planejador, é para ser transformada; o exemplo do intelectual político, algo muito complicado para quem também é da academia; o processo de formação da Sudene; e o fato de Furtado ter sido um intelectual que "não se coloca em caixinhas", que só servem à burocracia. Ele foi precursor "das abordagens interdisciplinares em desenvolvimento regional”. Para ela, que chegou à Sudene pouco tempo depois da cassação dos direitos políticos e do exílio de Furtado, sua utopia, hoje, é ver um mundo sem desigualdade, especialmente a regional e, sobretudo, a humana. Acredita, porém, que "o mundo tem andado para trás: a concentração da riqueza é tão absurda, que não cabe todo mundo".

Para Angelo Oswaldo, como intelectual, Celso Furtado sempre abordou a questão cultural como um dos pontos seminais da vida do país e de seu desenvolvimento socioeconômico. Não só na obra acadêmica, mas também na militância política. O legado de Celso Furtado, para Oswaldo, que foi seu chefe de gabinete no Ministério da Cultura, é o entendimento de que, sem se fundar na cultura, o desenvolvimento se torna frágil e vulnerável, incapaz de responder à realidade do país e de sua população. Por isso, chamava atenção para a cultura nas escolas, nos presídios e nos asilos, destacava o advento da transformação tecnológica, analisava a globalização, apontava disparidades regionais e a necessidade de compreender os desafios das cidades e dos territórios. A atuação política de Furtado, nas lembranças de Oswaldo, sempre esteve voltada para a causa republicana e democrática, para a superação da miséria e a valorização da originalidade do Brasil como povo e país. 
Abrimos o bloco Do Brasil para o mundo com o depoimento de Osvaldo Sunkel, um dos grandes parceiros de Celso Furtado desde os tempos da Cepal, que concentra sua atenção na atualidade do pensamento do nosso homenageado. Diz ele que o pensamento de Furtado ainda é absolutamente válido. Trata-se de leitura obrigatória para qualquer pessoa interessada em desenvolvimento nos turbulentos dias de hoje. Sunkel revela um desejo: "eu certamente gostaria de perguntá-lo sobre tudo isso que vem acontecendo nos últimos 20 anos, que está reconfigurando completamente o mundo, com grandes transformações geoeconômicas, políticas e demográficas". Para o economista chileno, Celso Furtado insistiu muito na possibilidade de que os países da América Latina "tivessem um pensamento e uma cultura de desenvolvimento a partir de dentro". No seu ponto de vista, quem quiser entender o que está se passando nas últimas décadas não tem escapatória: terá que ler Furtado.

No segundo depoimento deste bloco, o economista Argentino Aldo Ferrer (1927-2016) assegura que o pensamento de Celso Furtado foi e é de absoluta validade, sobretudo, agora que vivemos sob a influência do neoliberalismo e do conservadorismo. "Voce vê as coisas de forma diferente e sabe que os resultados foram muito ruins. E aí reaparece novamente a validade do pensamento de Celso, de Prebisch, Oswaldo Sunkel, do estruturalismo latino-americano". No entendimento de Ferrer, assim que recuperarmos "o bom senso, as ideias de Furtado voltarão à primeira fila”. A exemplo de Furtado, ao longo da vida, o nosso entrevistado se dividiu entre dois universos tensos: o ensino e a pesquisa, e a atividade pública. Quando foi ministro da economia, entre 1958-6o, Ferrer lembra que, inspirado em Furtado, também criou uma agência de planejamento regional para as províncias de Buenos Aires e de Chubut, à semelhança da Sudene, respeitadas as particularidades locais.

Gonzalo Martner Fanta foi aluno de Celso Furtado no começo dos anos 1970, na Sorbonne, em Paris. O doutorado foi uma recomendação do mestre numa visita feita aos pais de Martner Fanta, então exilados na Venezuela, vítimas da perseguição da ditadura do general Pinochet, no Chile. Na entrevista, Gonzalo conta particularidades do professor e o descreve como "extremamente cordial e atencioso". Discorre sobre a Cepal que, no seu entendimento, cumpriu um papel importante no sentido de incentivar os governos da América Latina a refletirem sobre a equidade e sobre o uso do boom das matérias-primas na geração de 
políticas eficazes para reduzir as desigualdades. Afirma acompanhar de perto os problemas políticos do Brasil, dada a importância do país para a América Latina: "o Brasil é um dos atores globais. Para todos nós é chocante ver que o emergente Brasil, player global, passa a ser um país em crise, um país emergente em recessão”. Sobre o futuro é enfático: "a reconstrução de uma visão a médio e longo prazo da América Latina deve partir do Brasil, eu acredito, porque o Brasil é o centro da economia latino-americana”, conclui.

O último depoimento do terceiro bloco é do sociólogo estadunidense Immanuel Wallerstein (1930 - 2019). Ele discute, dentre outras questões, a tese central do "cepalismo": a dualidade centro/periferia como um conceito para estruturar, visualizar e analisar a economia-mundo. Na sua opinião, isso pode ter vários significados: primeiro, o comércio internacional não tem efeitos neutros; segundo, essa antinomia implica que é preciso pensar em termos de mudanças estruturais para modificar essa situação de desenvolvimento desigual; e, por fim, Furtado nos mostra que a história importa e é fundamental. Para o sociólogo, tendemos a não nos surpreender que Furtado tenha feito história econômica, mas isso não é óbvio. A maioria dos economistas rejeita absolutamente tal abordagem, considerando-a sem importância. No entanto, neste contexto, assume todo o seu significado e se encaixa, na sua opinião, nesse todo que chama de "cepalismo". Wallerstein explica que se pode - e no nosso entendimento é urgente - pensar em construir um desenvolvimento no qual o Estado seja convocado a desempenhar um papel importante.

O quarto bloco (Utopias furtadianas) traz, já na abertura, o depoimento do economista Luiz Gonzaga Belluzzo, que conhece a obra de Celso Furtado como pouquíssimos. Belluzzo nos ensina que "a grande virtude de Celso Furtado é essa concepção de desenvolvimento como um fenômeno que procura entender [...] a dinâmica das estruturas". Ele "vai mostrando como as configurações da economia mundial vão se transformando e vão mudando a posição dos países envolvidos. Celso Furtado, de acordo com Belluzzo, partia da totalidade para observar as singularidades. Dizia que Prebisch olhava sincronicamente os vários momentos da relação centro-periferia e ele (Furtado) em perspectiva diacrônica, ou seja, histórica. Furtado, na leitura de Belluzzo, não se considerava um economista, mas sim, um servidor público, um homem interessado nos problemas brasileiros e que sabia usar a imaginação para pensar a situação dos países periféricos. 
O economista e professor aposentado da UFPE, Jorge Santana, em depoimento por escrito, afirma que foi somente sob a forte pressão dos movimentos sociais, dos mais destacados líderes religiosos, do empresariado industrial sediado no Sudeste, da imprensa regional e nacional e dos governadores mais antenados com o desenvolvimento socioeconômico do País e do mundo, que o projeto Sudene, que representava a ideia de "poder sem dono", foi aprovado pelo Congresso (em dezembro de 1959). Só que, uma vez instalada, passou a atemorizar "os donos do poder". Santana trabalhou na Sudene ao longo de 28 anos. Chegou dois anos depois da cassação dos direitos políticos e exílio de Furtado e testemunhou a instituição perder força e se esvaziar. E com isso, segundo ele, deixou passar a oportunidade histórica de aprofundar as propostas de desburocratização, transparência, moralidade, compromisso com posturas republicanas, justiça e inclusão social, integração socioeconômica e territorial horizontalizada e real abertura democrática, que só se alcança na vigência de um genuíno "poder sem donos".

Um outro depoimento forte, encaminhado por escrito aos organizadores deste volume, é o do professor de economia política da Universidad Santiago de Compostela, José Ramón García Menéndez. Ele, no começo dos anos 1970, interagiu com Celso Furtado em "momentos, encruzilhadas, trilhas nas que você coincide com outros caminhantes que, sem pretender, estão marcando e moldando sua própria trajetória”. O depoimento que reproduzimos constitui "uma leitura nostálgica e apaixonada" que também "interpreta e reconstrói”. Passaram-se quase cinco décadas, segundo Menéndez, desde o primeiro encontro. Termos como "coerência", "dignidade", "compromisso", "honestidade intelectual", "ambição teórica", "serviço público", "talento", "sensibilidade social", "dedicação", segundo ele, podem ser conjugados, simultaneamente, como formulados (e vividos) por Furtado, talvez com contradições, mas sem hipocrisia intelectual. A última lição do professor para o aprendiz.

O último depoimento deste volume é do saudoso economista e professor Carlos Lessa. Foi apresentado em seminário organizado pelo Centro Internacional Celso Furtado, que teve como objetivo, de um lado, repensar o desenvolvimento, depois de mais de duas décadas de prevalência do ideário neoliberal, que escamoteou os problemas estruturais e impediu estratégias e políticas de superação do subdesenvolvimento; e, de outro, retomar as ideias do economista paraibano para, a partir delas, oferecer uma contribuição intelectual indispensável para 
que se refaçam diagnósticos e se formulem agendas públicas de uma política econômica transformadora. Carlos Lessa morreu no dia 5 de maio de 2020. Na homenagem que prestou a Celso Furtado reside a nossa ao próprio Lessa, por tudo que representou para a interpretação e transformação do Brasil contemporâneo.

\section{Acerto de contas}

Os depoimentos e entrevistas de amigos, colegas, colaboradores, ex -alunos, interlocutores de Celso Furtado que se enfileiram nas páginas a seguir são, por diversos motivos, registros únicos. Não que não pudesse haver outros. Aliás, há outros. Existem inúmeros, uns não tão conhecidos, outros já imortalizados que o ilustre economista paraibano, por alguma boa razão, chamou à superfície. Mas, nesta singela coletânea, reivindicamos uma pequena originalidade: quase tudo foi obtido - em um ou outro caso, 'extraído' - "a quente", isto é, quase tudo deriva da memória, da reminiscência e da lembrança de pessoas de sua convivência com um dos maiores intelectuais que o Brasil já teve. Nem tudo o que se vai ler favorece a construção de uma imagem imaculada, angelical, inocente. Afinal, Celso Furtado era humano. Aqui não censuramos as palavras de quem, tendo convivido com ele, percebeu virtudes e defeitos. Todavia, não alimentamos o fuxico, a fofoca, o mal-entendido.

Essa advertência antecipa aos leitores que Celso Furtado era alguém que, como qualquer de seus semelhantes, acertou e errou ao longo de seus 84 anos intensamente vividos. Procuramos jogar um pouco de luz sobre algumas daquelas qualidades que o tornaram um ser humano tão singular. Os depoimentos e entrevistas revelam um Celso Furtado humilde, capaz de ouvir seus interlocutores com a atenção e confiar plenamente nos integrantes das equipes que constituiu. Um Celso Furtado preocupado com a qualificação interdisciplinar de sua equipe e rigoroso no uso de dados e na revisão de relatórios. Um Celso Furtado capaz de articular as melhores competências para perseguir uma causa e, ao mesmo tempo, zeloso, ao extremo, no uso de recursos públicos. Um Celso Furtado hábil na negociação política, inclusive, com eventuais adversários - mas, nunca ao preço dos princípios e valores que guiaram sua atuação na esfera pública. Um Celso Furtado dedicado e disciplinado quando (desafiado intelectualmente) se tratava de desvendar e entender algo que ainda não era de seu domínio, e capaz de compartilhar e submeter seus escritos, antes da publicação, à crítica dos colegas 
e colaboradores. Um Celso Furtado que, por trás de sua sempre reta atuação na esfera pública, tinha uma singular visão de futuro.

Mas, a visão de futuro de Celso Furtado restringiu-se, apenas, à emancipação dos nordestinos, ou incluiu os demais brasileiros? Quanto 'internacionalismo' cabia na sua visão? Os depoimentos e entrevistas a seguir oferecem pistas seguras de um Celso Furtado permanentemente preocupado com os fragilizados, os desfavorecidos, os destituídos, sim, os explorados. E com as relações que reproduzem a discriminação, o favor, a exploração. Daí seu olhar mais atento, embora nunca xenofóbico, para a América Latina, para o Brasil, para o Nordeste. Sua visão de futuro tinha, em seu centro, uma excessiva generosidade para com o gênero humano, sobretudo, lá onde predominava a discriminação, o favor, a exploração. Essa singular visão de futuro não era um passivo "esperar para ver no que vai dar" em algum momento distante do tempo presente. Era, ao contrário, uma ativa e incansável disposição de construir, desde já e com inteligência, um "aqui e agora". Também não era um delírio intelectual inconsequente, que desconhecia as relações concretas de poder que vigoravam nas sociedades marcadas pela discriminação, pelo favor, pela exploração.

Em um ensaio de 1997, que trazia o sugestivo título "A longa marcha da utopia”, Furtado (1998) enaltecia "a crescente participação da população organizada no controle dos centros de poder, ou seja, a democratização do poder" (p. 22), e considerava a política "a esfera mais nobre das atividades criativas humanas” (p. 23). Os depoimentos e entrevistas deste volume podem ser lidos como verdades, mas também como versões de fatos, como imagens que saltam de reminiscências, como quadros parciais da história que cada depoente e entrevistado conta a partir da sua relação com o economista, com o ministro, com o humanista, com o intelectual, com o professor. Porém, o propósito de reuni-los nesta coletânea terá sido alcançado se deles emergir um Celso Furtado que traduza fidedignamente o ser humano que acertou e errou, e que tinha uma singular visão de futuro que privilegiava a emancipação das vítimas da descriminação e da exploração, a partir de sua crescente participação "no controle dos centros do poder". Uma visão de futuro que há de nos inspirar a superar, uma vez mais, "a distância entre o que somos e o que esperávamos ser" (FURTADO, 1999, p. 26). 


\section{Referências}

Celso Furtado: o desvelador da realidade nordestina. Recife: Fundação Joaquim Nabuco, Editora Massangana, 2017. 128 p.

FURTADO, Celso. "A busca de novo horizonte utópico". In: O longo amanhecer: reflexões sobre a formação do Brasil. Rio de Janeiro: Paz e Terra, 1999, p. 13-26.

FURTADO, Celso. "A longa marcha da utopia". In: O capitalismo global. 2 ed. São Paulo: Paz e Terra, 1998, p. 9-23. 